\title{
A Novel Method for the Protection and Activation of Histidine*
}

\author{
Yinan Zhao ${ }^{1,2}$, Shubiao Zhang', Shaohui Cui ${ }^{1}$, Huiying Chen ${ }^{1}$, Bing Wang ${ }^{1}$, Shufen Zhang ${ }^{2}$ \\ ${ }^{1}$ Key Laboratory of Bio-chemistry Engineering, The State Ethnic Affairs Commission-Ministry of Education, \\ Dalian Nationalities University, Dalian, China \\ ${ }^{2}$ State Key Laboratory of Fine Chemicals, Dalian University of Technology, Dalian, China \\ Email: zsb@dlnu.edu.cn, zhangshf@dlut.edu.cn
}

Received 2012

\begin{abstract}
The yield and purity of synthetic peptides were greatly related to the amino acid protection and activation during the synthesis process. Therefore, the amino acid protection and activation are the most important steps in peptide synthesis. By using tetrahydrofuran as the solvent, 9-fluorenylmethoxycarbonyl as protection group, 2-(7-azobenzotri- azol-1-yl)-N,N,N',N'-tetramethyluronium hexaflu- orophosphate (HATU) as condensation reagent an amino protected histidine ester was given. In this article a novel synthesis method for $\mathrm{N}$-(9- fluorenylmethoxycarbonyl)-histidine active ester was established. The reaction conditions for preparing this active ester were optimized. The experimental results indicated that solvents and active reagents had remarkable effects on the yield of active ester. The best conditions for preparing the active ester was a ratio of $n$ (Fmoc-His-OH): $n$ (HATU) = 1:1.2 with THF used as the solvent at room temperature. The yield of the final product was about $80 \%$ with a purity of over $85 \%$. This simple method would provide fundamentals for the synthesis of other protected amino acid active esters.
\end{abstract}

Keywords: Histidine; Protection; Activation; Peptide

\section{Introduction}

Proteins and peptides are important classes of bioactive macromolecules that play key roles in controlling biological functions. Peptides often have a specific biological signal; and they can significantly improve the adhesion of cells on the surface [1]. Indeed, there are numerous preclinical and clinical trials using proteins or peptides. These macromolecules are also widely used as biochemical or pharmacological tools, especially peptides which are available at high purity grade by large-scale chemical synthesis. With the development of polypeptide drugs, various fields of scientist from chemistry, biology and medicine are paying more and more attention to the research of this kind of new drugs. Recent years peptides and their derivatives have been used for restraining cancer cell migration, curing anti-thrombosis, treating acute renal failure, reducing anti-inflammation and promoting skin regeneration, etc $[2,3]$. Especially people found that the introduction of peptide groups into cationic lipids can prolong their half-life in vivo and enhance targeting thereof. The value of cationic liposomes with peptides for the delivery of genetic materials has been realized gradually by researchers [4,5], as they have many advantages, including numerous free active functional groups on their surface, avirulence, used either in vitro or in vivo [6-8], no obvious limits for materials contained in size, no inflammation, and the control of the amount of the materials into the cells [8]. Moreover, they maintain their physiological concentration advantages, most amino groups have been protonated in the process of carrying genes, and thereby with positive charge they could combine with negatively charged plasmid DNA to

\footnotetext{
*The study was supported by the National Natural Science Foundation of China (20876027 and 21176046) and the Fundamental Research Funds for the Central Universities(DC12010104).
}

form liposomes/DNA complexes by electrostatic attraction [6]. All the applications will depend on the artificial peptide synthesis through the controlled connection of different amino acids. The key difficulty is that the reagents used for the peptide connection can easily react with other groups such as the amino groups at the $\mathrm{N}$-terminal of residues, carboxylic groups at the C-ter- minal of residues, reactive groups on the side chains and especially much more active $\mathrm{SH}$ groups. Therefore, in order to obtain the synthetic peptide with specific order, people can only use the method of stereospecific synthesis step by step. Before the connection of different amino acids was performed, these reactive groups must be blocked or protected to avoid the side reaction with the activated reagents. In this paper, we elucidated a novel method for the simple synthesis and purification of protected histidine active ester, which would lay a foundation of the large scale synthesis of peptides. The results herein also showed much improvement over our previous study [9].

\section{Materials and Methods}

\subsection{Materials}

All the reagents employed in the synthesis of active ester were of analytical purity. Methylene dichloride $\left(\mathrm{CH}_{2} \mathrm{Cl}_{2}\right)$, tetrahydrofuran (THF), ethyl acetate and ethyl ether were purchased from Shanghai Chemical Industry Co., Ltd. (Shanghai, China). Histidine, N-(9-Fluorenylmethoxycarbony loxy) succinimide (Fmoc-OSu), Boc-Gly-OH, O-(7-Azabenzotriazole-1-yl)- N,N, $\mathrm{N}^{\prime}, \mathrm{N}^{\prime}$-tetramethyl uranium (HATU) were purchased from Shanghai Medpep Co., Ltd. (Shanghai, China).

\subsection{Instruments}

Rotary evaporator, Shanghai Yarong Biochemistry Instrment 
Factory (Shanghai, China); Vacuum drying oven, DHG-9070A, Shanghai Jing Hong Laboratory Instrument Co., Ltd. (Shanghai, China); Infrared Spectrometer, NICOLET370, Thermo Electron Co., Ltd. (United States); HPLC-MS, SHIMADZU Co., Ltd. (Japan).

\subsection{Synthesis of 9-Fluorenylmethoxycarbonyl- L-His-OH}

$\mathrm{N}$-(9-Fluorenylmethoxycarbonyloxy) succinimide was used to protect the amino group of Histidine to obtain 9-Fluorenylmethoxycarbonyl-L-His-OH (Fmoc-His-OH) during a one-step process which is depicted in Scheme 1. In this one-step process, histidine was dissolved in $25 \mathrm{~mL}$ distilled water, Fmoc-OSu in 20mL THF. Then Histidine solution was added to Fmoc-OSu solution slowly, following the adjustment of $\mathrm{pH}$ of $8-9$ by using $10 \%$ sodium hydroxide and reaction at room temperature for $2 \mathrm{~h}$. After the reaction, the mixture fluid was extracted with ethyl ether for three times, and then $20 \mathrm{~mL}$ distilled water was added following the adjustment of $\mathrm{pH}$ to 3 with $10 \%$ hydrochloride. After extracted with ethyl acetate for three times, the organic phase was washed with the $5 \%$ citric acid, saturated salt water and distilled water, respectively. The solution was dried with anhydrous magnesium sulfate and the solvent was removed by rotary evaporation. Finally the residual powder was subject to recrystallization through ethyl ether.

\subsection{Synthesis of}

\section{9-Fluorenylmethoxycarbonyl-L-Histidine Anhydrid}

9-Fluorenylmethoxycarbonyl-L-histidine ester, whose synthesis process is depicted in Scheme 2. In this synthesis process, 9Fluorenylmethoxycarbonyl-L-His-OH (3mmol) was dissolved in $20 \mathrm{~mL}$ THF, HATU (3.6mmol) was dissolved in $20 \mathrm{~mL}$ acetonitrile, the two solutions were dropwise mixed slowly at room temperature and kept reaction for $16 \mathrm{~h}$. After the reaction was completed, the solution was washed with $\mathrm{CH}_{2} \mathrm{Cl}_{2}$ and solvent was removed by rotary evaporation. The final product with the yield of $80 \%$ or so and the purity of over $85 \%$ was obtained through recrystallization from ethyl acetate for three times.

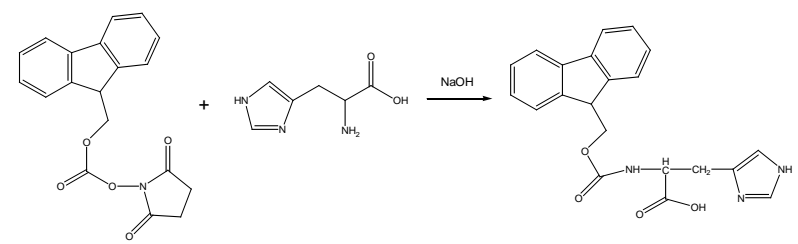

Scheme 1. Synthesis of 9-Fluorenylmethoxycarbonyl-L-His-OH.

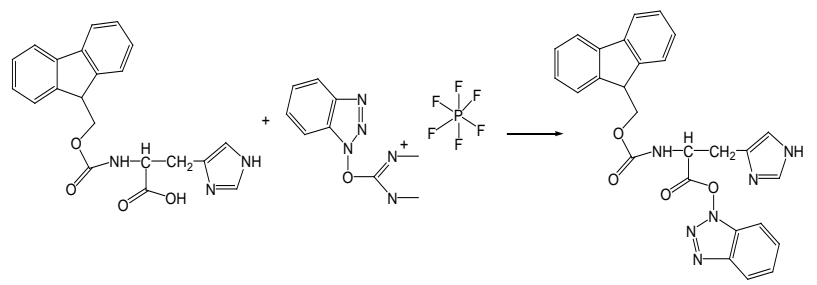

Scheme 2. Synthesis of 9-Fluorenylmethoxycarbonyl-L-Histidine ester.

\section{Results}

Many studies have shown that the amino acid protection and activation have great influence on yield and purity of 9-Fluorenylmethoxycarbonyl-L-Histidine ester. Solvent and other reagents used have influences on protection and activation. Through the study of protection and activation of histidine, the optimum conditions of amino acid activation were $n$ (FmocHis-OH): $n$ (HATU) $=1: 1.2$ by using tetrahydrofuran as the solvent at the temperature of room temperature. The analytical results of chemical structure of the active ester are listed below as shown in Figures $\mathbf{1}$ and $\mathbf{2}$ of IR, and Figures $\mathbf{3}$ and $\mathbf{4}$ of MS.

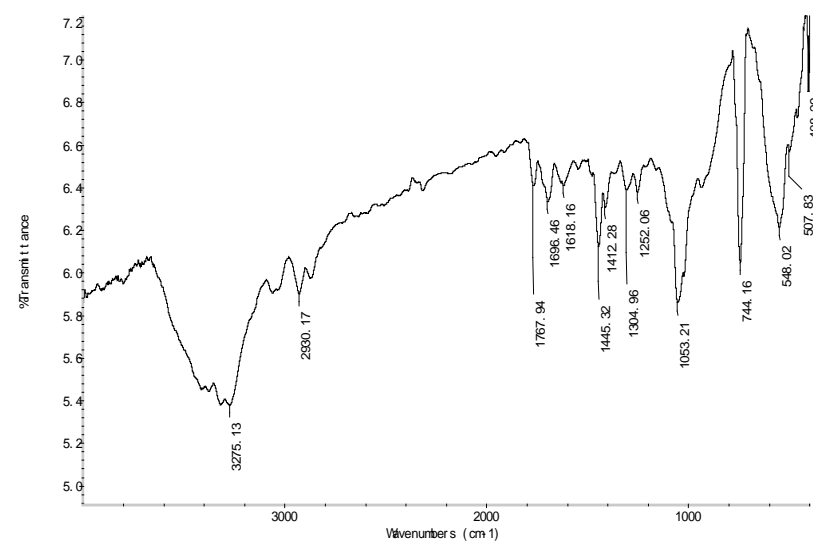

Figure 1. The infrared spectrum of 9-Fluorenylmethoxycarbony l-L-His-OH.

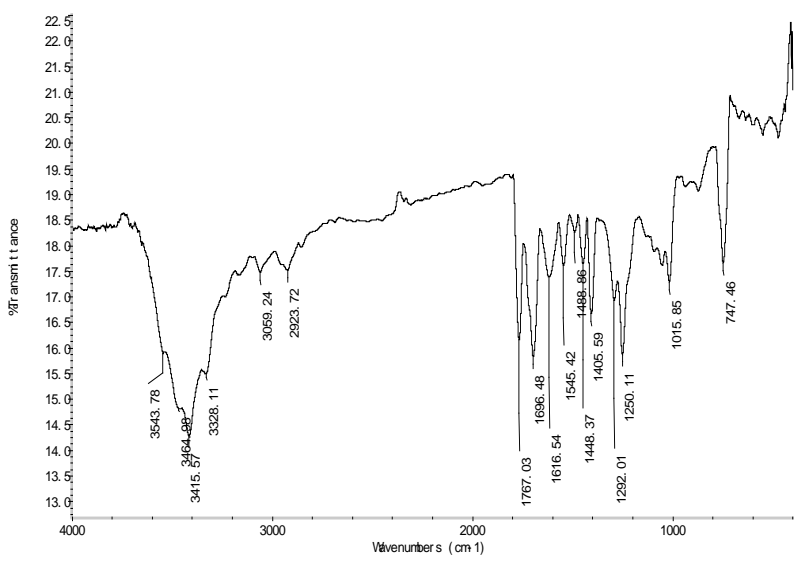

Figure 2. The infrared spectrum of 9-Fluorenylmethoxycarbonyl$L$-Histidine ester.

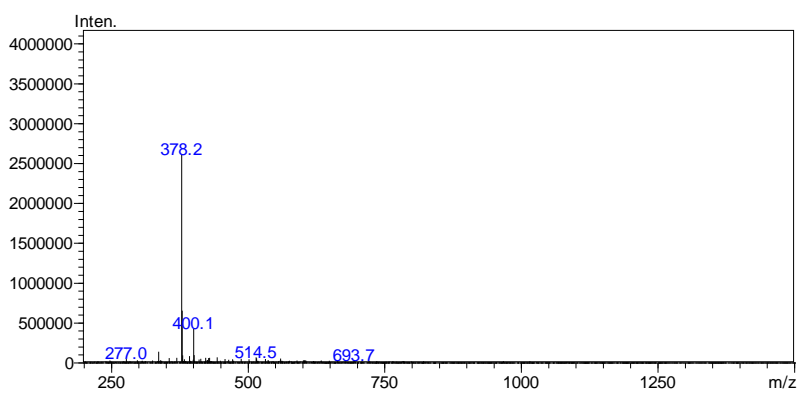

Figure 3. The mass spectrum of 9-Fluorenylmethoxycarbonyl- $L$ His-OH. 


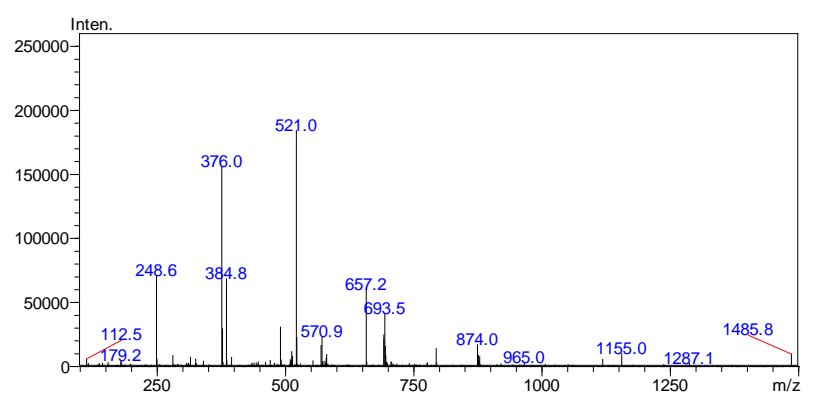

Figure 4. The mass spectrum of 9-Fluorenylmethoxycarbonyl-LHistidine ester.

Fmoc-His-OH: ESI-MS m/z 377.53[M], $378.53[\mathrm{M}+\mathrm{H}]^{+}$, $400.53[\mathrm{M}+\mathrm{Na}]^{+}$. IR $v / \mathrm{cm}^{-1}: 3300-3400\left(v_{\mathrm{NH}}\right), 3275.13(\mathrm{OH})$, 2950.27-2853.67( $\left.v_{\mathrm{CH}}\right), 1767.94\left(v_{\mathrm{C}=\mathrm{O}}\right), 1252.06$ and 1053.21 (Fmoc $v_{\mathrm{C}-\mathrm{O}-\mathrm{C}}$ ), 744( $\left.\delta_{\mathrm{CH}}\right)$.

9-Fluorenylmethoxycarbonyl-L-Histidine ester: ESI-MS $\mathrm{m} / \mathrm{z}, 493.18[\mathrm{M}], 248.6[\mathrm{M}+2 \mathrm{H}]^{+}, 376,384.8$ (segment peaks). IR $v / \mathrm{cm}^{-1}: \quad 3328.11 \sim 3464.98\left(v_{\mathrm{NH}}\right), \quad 2950.27-2923.72\left(v_{\mathrm{CH}}\right)$, 1767.03 1696.48( $\left.v_{\mathrm{C}=\mathrm{O}}\right), 1292.01$ and 1250.11 ( $v_{\text {OCOCO }}$ ).

\section{Discussion}

The results showed that the solvent system and dosage of activation reagent HATU have great influence on yield and purity of 9-Fluorenylmethoxycarbonyl-L-Histidine ester. The yield of active ester could be greatly improved by using infirm polarity of tetrahydrofuran as the solvent system. The light excess of HATU was also beneficial to the yield. During the process of 9-Fluorenylmethoxycarbonyl- $L$-His-OH synthesis, the $\mathrm{pH}$ of reaction system must be kept between 9 10, otherwise, activity of Fmoc-OSu could be greatly lowered. On the other hand, the rapid dropping speed could cause inadequate reaction. In the purification process, we have tried many other solvents including ethanol, acetone, toluene, and so on. It was finally found that acetate ester was the best solvent for the recrystallization of both of 9-Fluorenylmethoxycarbonyl-L-His-OH, and 9-Fluorenyl- methoxycarbonyl-L-His ester. This study provided a novel method for the simple synthesis and purification of protected histidine active ester. This yield was highly improved compared with the previous experiment [9], and the purity of product was also well increased. Base on the study of the pro- tection and activation of histidine, we have built up a method for the synthesis and purification of other amino acids, which could forward the synthesis of peptides for the drugs and drug delivery systems.

\section{Acknowledgements}

The study was supported by the National Natural Science Foundation of China (20876027 and 21176046) and the Fundamental Research Funds for the Central Universities (DC12010104).

\section{REFERENCES}

[1] S. B. Zhang, Y. N. Zhao, and B. D. Zhao. "Hybrids of nonviral vectors for gene delivery,” Bioconjugate Chem. vol. 21, pp. 1003-1009, June 2010.

[2] D. J. Coles, A. Esposito, and H. T. Chuah. "The synthesis and characterization of lipophilic peptide-based carriers for gene delivery,” Tetrahedron. vol. 66, pp.5435-5441, July 2010.

[3] Y. T. Ko, C. Falcao, and V. P. Torchilin. "Cationic liposomes loaded with proapoptotic peptide D-(KLAKLAK)2 and Bcl-2 antisense oligodeoxynucleotide G3139 for enhanced anticancer therapy,”Molecular Pharmaceutics, vol.6,pp.971-977, March 2009.

[4] D. L. McKenzie, K. Y. Kwok, and K. G. Rice. “A potent new class of reductively activated peptide gene delivery agents,” J. Biol. Chem., vol. 275, pp. 9970-9977, April 2000.

[5] M. A. Mintzer, E. E. Simanek. "Nonviral vectors for gene delivery,” Chem Rev., vol. 109, pp.259-302, April 2009.

[6] M. Nishikawa, M. Yamauchi, and K. Morimoto. "Heptocyte-targeted in vivo gene expression by intraveneous injection of plasmid DNA complexed with synthetic multi-functional gene delivery system,” Gene Ther.,vol. 7, pp.548-555, July 2000.

[7] M. J. Schuster, G. Y. Wu, and C. M.Walton. "Multicomponent DNA carrier with a vesicular stomatitis virus G-peptide greatly enhaances liver-targeted gene expression in mice,"Bioconjugate Chem.,vol.10, pp.1075-1083, October 1999.

[8] S. B. Zhang, Y. M. Xu, and B.Wang. "Cationic compounds used in lipoplexes and polyplexes for gene delivery,” J.Control Release, vol. 100, pp.165-180, November 2004.

[9] Y. N. Zhao,S. B. Zhang, and S. H. Cui. "Preparation of amino acid active ester in peptide intermediate,” Chemical Word, vol.2, pp. 105-109, February 2012. 